Article

\title{
Study of Structure and Permeability Relationship of Flavonoids in Caco-2 Cells
}

\author{
Yajing Fang, Weiwei Cao, Mengmeng Xia, Siyi Pan and Xiaoyun Xu * \\ Key Laboratory of Environment Correlative Dietology, Ministry of Education, \\ Huazhong Agricultural University, Wuhan 430070, China; fyj@webmail.hzau.edu.cn (Y.F.); \\ weiweicao@webmail.hzau.edu.cn (W.C.); xiamengmeng@webmail.hzau.edu.cn (M.X.); \\ Pansiyi@mail.hzau.edu.cn (S.P.) \\ * Correspondence: xuxiaoyun@mail.hzau.edu.cn; Tel.: +86-027-8767-1056; Fax: +86-027-8728-8373
}

Received: 3 November 2017; Accepted: 24 November 2017; Published: 29 November 2017

\begin{abstract}
Flavonoids exhibit a broad range of biological activities. However, poor absorption of some flavonoids is a major limitation for use of flavonoids as nutraceuticals. To investigate the structure requirements for flavonoids intestinal absorption, transepithelial transport and cellular accumulation (CA) of 30 flavonoids were determined using the Caco- 2 cell monolayer. The bilateral permeation of five types of flavonoids followed the order: flavanones $\geq$ isoflavones $>$ flavones $\geq$ chalcones $>$ flavonols. The concentration of flavonoids accumulated in cells did not correlate with cell penetration since the correlation coefficient between the apparent permeability coefficient $\left(P_{\text {app }}\right)$ and their corresponding $C A$ was poor $\left(R^{2}<0.3\right)$. Most flavonoids exhibited a ratio of $0.8-1.5$ for $P_{\text {app A to B }} / P_{\text {app B to A, suggesting passive }}$ diffusion pathways. However, luteolin, morin and taxifolin may involve the efflux mechanisms. The quantitative structure-permeability relationship (QSPR) study demonstrated that the intestinal absorption of flavonoids can be related to atomic charges on carbon $3^{\prime}\left(Q_{C 3^{\prime}}\right)$, molecule surface area (SlogP_V3), balance between the center of mass and position of hydrophobic region (vsurf_ID1) and solvation energy of flavonoids $\left(E \_s o l\right)$. These results provide useful information for initially screening of flavonoids with high intestinal absorption.
\end{abstract}

Keywords: Caco-2; flavonoids; intestinal absorption; permeability; QSPR

\section{Introduction}

Flavonoids which are produced by plants as secondary plant metabolites are one of the most widely distributed polyphenols. Structurally, flavonoids are derived from a parent nucleus, a diphenylpropane (C6-C3-C6) skeleton. Flavonoids are mainly divided into eight subclasses depending on the structure difference on $\mathrm{C}$ ring, including flavones, flavonols, flavanones, flavanonols, isoflavones, flavan-3-ols, flavan-3, 4-diols (flavandiol) and anthocyanins [1]. Flavonoids exhibit health benefits due to their various biological activities including antioxidant, anti-cancer [2], antimicrobial [3], anti-inflammation [4] and others. However, poor oral bioavailability of some flavonoids, caused by low epithelial transport and extensive metabolism, is a major limitation for use of flavonoids as nutraceuticals. Low bioavailability has been associated with flavonoid interactions at various stages of the digestion, absorption and distribution process, which are strongly affected by their molecular structures. Hence, an increase in absorption of flavonoids is one way to improve their oral bioavailability. Previous studies have shown that the molecular structures play an important role on the absorption of flavonoids, including the degree or position of substitution of hydroxyl and alkyl group [5], methoxyl group [6], prenyl group [7], and glycosidic group [8].

Numerous structure permeability relationship (SPR) studies of flavonoids have been investigated by comparing the difference of permeability/absorption data and structure of analogues. 
However, the application of SPR study has been limited due to lack of prediction for untested compounds. The quantitative structure activity relationship (QSAR) for flavonoids is gaining interest by quantitatively correlating the molecular structures or properties with variation in biological activity. But, few QSPR studies have been performed to investigate the intestinal absorption of flavonoids [9] and the absorption mechanisms for flavonoids are not well established.

Caco-2 monolayer model is widely used $[10,11]$ to estimate and predict the intestinal permeability of various flavonoids [5,12], because it is derived from human colonic adenocarcinoma and shares many morphological (e.g., microvilli) and functional properties with mature enterocytes. Caco-2 cells also exhibit a well-differentiated brush border on their apical surfaces and express many typical transporters and enzymes found in the small intestine [13,14]. An excellent correlation was found between the oral absorption of flavonoids in human and the apparent permeability $\left(P_{\text {app }}\right)$ in Caco-2 monolayer model when the $P_{\text {app }}$ is more than $10^{-6} \mathrm{~cm} / \mathrm{s}$ [15].

In this study, 30 flavonoids were investigated for their intestinal permeability and cellular accumulation (CA) by using the Caco-2 monolayer model. First, the tested flavonoids with diverse structures including flavones, flavonols, flavanones, flavanonols, isoflavones and chalcones were studied to obtain their SPR. To observe the effect of structure of flavonoids on their intestinal absorption, a 2D-QSPR model was developed using the $P_{\text {app }}$ values from apical to basolateral side ( $\left.P_{\text {app A to B }}\right)$ as the dependent variable and molecular descriptors as independent variables. The chemical structures of the 30 flavonoids tested are presented in Table 1.

Table 1. The chemical structures of 30 flavonoids.

\begin{tabular}{|c|c|c|c|c|c|c|c|c|c|c|c|}
\hline No. & Flavonoids & Core Structure & $\mathbf{R}_{3}$ & $\mathbf{R}_{5}$ & $\mathbf{R}_{6}$ & $\mathbf{R}_{7}$ & $\mathbf{R}_{8}$ & $\mathbf{R}_{2^{\prime}}$ & $\mathbf{R}_{3^{\prime}}$ & $\mathbf{R}_{4^{\prime}}$ & $\mathbf{R}_{5^{\prime}}$ \\
\hline 1 & Flavone & & $\mathrm{H}$ & $\mathrm{H}$ & $\mathrm{H}$ & $\mathrm{H}$ & $\mathrm{H}$ & $\mathrm{H}$ & $\mathrm{H}$ & $\mathrm{H}$ & $\mathrm{H}$ \\
\hline 2 & Tangertin & & $\mathrm{H}$ & $\mathrm{OMe}$ & $\mathrm{OMe}$ & $\mathrm{OMe}$ & $\mathrm{OMe}$ & $\mathrm{H}$ & $\mathrm{H}$ & $\mathrm{OMe}$ & $\mathrm{H}$ \\
\hline 3 & Wogonin & & $\mathrm{H}$ & $\mathrm{OH}$ & $\mathrm{H}$ & $\mathrm{OH}$ & $\mathrm{OMe}$ & $\mathrm{H}$ & $\mathrm{H}$ & $\mathrm{H}$ & $\mathrm{H}$ \\
\hline 4 & Baicalein & & $\mathrm{H}$ & $\mathrm{OH}$ & $\mathrm{OH}$ & $\mathrm{OH}$ & $\mathrm{H}$ & $\mathrm{H}$ & $\mathrm{H}$ & $\mathrm{H}$ & $\mathrm{H}$ \\
\hline 5 & Luteolin & & $\mathrm{H}$ & $\mathrm{OH}$ & $\mathrm{H}$ & $\mathrm{OH}$ & $\mathrm{H}$ & $\mathrm{H}$ & $\mathrm{OH}$ & $\mathrm{OH}$ & $\mathrm{H}$ \\
\hline 6 & Apigenin & & $\mathrm{H}$ & $\mathrm{OH}$ & $\mathrm{H}$ & $\mathrm{OH}$ & $\mathrm{H}$ & $\mathrm{H}$ & $\mathrm{H}$ & $\mathrm{OH}$ & $\mathrm{H}$ \\
\hline 7 & Chrysin & & $\mathrm{H}$ & $\mathrm{OH}$ & $\mathrm{H}$ & $\mathrm{OH}$ & $\mathrm{H}$ & $\mathrm{H}$ & $\mathrm{H}$ & $\mathrm{H}$ & $\mathrm{H}$ \\
\hline 8 & Schaftoside & & $\mathrm{H}$ & $\mathrm{OH}$ & Cglc & $\mathrm{OH}$ & Carb & $\mathrm{H}$ & $\mathrm{H}$ & $\mathrm{OH}$ & $\mathrm{H}$ \\
\hline 9 & Galangin & & $\mathrm{OH}$ & $\mathrm{OH}$ & $\mathrm{H}$ & $\mathrm{OH}$ & $\mathrm{H}$ & $\mathrm{H}$ & $\mathrm{H}$ & $\mathrm{H}$ & $\mathrm{H}$ \\
\hline 10 & Quercetin & & $\mathrm{OH}$ & $\mathrm{OH}$ & $\mathrm{H}$ & $\mathrm{OH}$ & $\mathrm{H}$ & $\mathrm{H}$ & $\mathrm{OH}$ & $\mathrm{OH}$ & $\mathrm{H}$ \\
\hline 11 & Morin & & $\mathrm{OH}$ & $\mathrm{OH}$ & $\mathrm{H}$ & $\mathrm{OH}$ & $\mathrm{H}$ & $\mathrm{OH}$ & $\mathrm{H}$ & $\mathrm{OH}$ & $\mathrm{H}$ \\
\hline 12 & Kaempferol & & $\mathrm{OH}$ & $\mathrm{OH}$ & $\mathrm{H}$ & $\mathrm{OH}$ & $\mathrm{H}$ & $\mathrm{H}$ & $\mathrm{H}$ & $\mathrm{OH}$ & $\mathrm{H}$ \\
\hline 13 & Kaempferide & & $\mathrm{OH}$ & $\mathrm{OH}$ & $\mathrm{H}$ & $\mathrm{OH}$ & $\mathrm{H}$ & $\mathrm{H}$ & $\mathrm{H}$ & $\mathrm{OMe}$ & $\mathrm{H}$ \\
\hline 14 & Myricetin & & $\mathrm{OH}$ & $\mathrm{OH}$ & $\mathrm{H}$ & $\mathrm{OH}$ & $\mathrm{H}$ & $\mathrm{H}$ & $\mathrm{OH}$ & $\mathrm{OH}$ & $\mathrm{OH}$ \\
\hline 15 & Isorhamnetin & & $\mathrm{OH}$ & $\mathrm{OH}$ & $\mathrm{H}$ & $\mathrm{OH}$ & $\mathrm{H}$ & $\mathrm{H}$ & $\mathrm{OMe}$ & $\mathrm{OH}$ & $\mathrm{H}$ \\
\hline 16 & Quercitrin & & Orha & $\mathrm{OH}$ & $\mathrm{H}$ & $\mathrm{OH}$ & $\mathrm{H}$ & $\mathrm{H}$ & $\mathrm{OH}$ & $\mathrm{OH}$ & $\mathrm{H}$ \\
\hline 17 & Rutin & & ORG & $\mathrm{OH}$ & $\mathrm{H}$ & $\mathrm{OH}$ & $\mathrm{H}$ & $\mathrm{H}$ & $\mathrm{OH}$ & $\mathrm{OH}$ & $\mathrm{H}$ \\
\hline 18 & Hesperetin & & $\mathrm{H}$ & $\mathrm{OH}$ & $\mathrm{H}$ & $\mathrm{OH}$ & $\mathrm{H}$ & $\mathrm{H}$ & $\mathrm{OH}$ & $\mathrm{OMe}$ & $\mathrm{H}$ \\
\hline 19 & Naringenin & & $\mathrm{H}$ & $\mathrm{OH}$ & $\mathrm{H}$ & $\mathrm{OH}$ & $\mathrm{H}$ & $\mathrm{H}$ & $\mathrm{H}$ & $\mathrm{OH}$ & $\mathrm{H}$ \\
\hline 20 & Naringin & & $\mathrm{H}$ & $\mathrm{OH}$ & $\mathrm{H}$ & ONG & $\mathrm{H}$ & $\mathrm{H}$ & $\mathrm{H}$ & $\mathrm{OH}$ & $\mathrm{H}$ \\
\hline 21 & Liquiritigenin & & $\mathrm{H}$ & $\mathrm{H}$ & $\mathrm{H}$ & $\mathrm{OH}$ & $\mathrm{H}$ & $\mathrm{H}$ & $\mathrm{H}$ & $\mathrm{OH}$ & $\mathrm{H}$ \\
\hline 22 & Taxifolin & & $\mathrm{OH}$ & $\mathrm{OH}$ & $\mathrm{H}$ & $\mathrm{OH}$ & $\mathrm{H}$ & $\mathrm{H}$ & $\mathrm{OH}$ & $\mathrm{OH}$ & $\mathrm{H}$ \\
\hline 23 & Formononetin & & - & $\mathrm{H}$ & $\mathrm{OH}$ & $\mathrm{H}$ & $\mathrm{H}$ & $\mathrm{H}$ & $\mathrm{OMe}$ & $\mathrm{H}$ & $\mathrm{H}$ \\
\hline 24 & Puerarin & & - & $\mathrm{H}$ & $\mathrm{H}$ & $\mathrm{OH}$ & Cglc & $\mathrm{H}$ & $\mathrm{H}$ & $\mathrm{OH}$ & $\mathrm{H}$ \\
\hline 25 & Glycitein & & - & $\mathrm{H}$ & $\mathrm{OMe}$ & $\mathrm{OH}$ & $\mathrm{H}$ & $\mathrm{H}$ & $\mathrm{H}$ & $\mathrm{OH}$ & $\mathrm{H}$ \\
\hline 26 & Daidzein & & - & $\mathrm{H}$ & $\mathrm{H}$ & $\mathrm{OH}$ & $\mathrm{H}$ & $\mathrm{H}$ & $\mathrm{H}$ & $\mathrm{OH}$ & $\mathrm{H}$ \\
\hline 27 & Genistein & & - & $\mathrm{OH}$ & $\mathrm{H}$ & $\mathrm{OH}$ & $\mathrm{H}$ & $\mathrm{H}$ & $\mathrm{H}$ & $\mathrm{OH}$ & $\mathrm{H}$ \\
\hline 28 & Biochanin A & & - & $\mathrm{OH}$ & $\mathrm{H}$ & $\mathrm{OH}$ & $\mathrm{H}$ & $\mathrm{H}$ & $\mathrm{H}$ & $\mathrm{OMe}$ & $\mathrm{H}$ \\
\hline 29 & Isoliquiritigenin & & $\mathrm{OH}$ & $\mathrm{OH}$ & - & - & - & $\mathrm{H}$ & $\mathrm{H}$ & $\mathrm{OH}$ & $\mathrm{H}$ \\
\hline 30 & $\begin{array}{l}\text { Neohesperidin } \\
\text { dihydrochalcone }\end{array}$ & & NG & $\mathrm{OH}$ & - & - & - & $\mathrm{H}$ & $\mathrm{OH}$ & $\mathrm{OMe}$ & $\mathrm{H}$ \\
\hline
\end{tabular}

Cglc: -C-glucopyranosyl; Carb: -O-( $\alpha$-L-Arabinopyranosyl); Orha: -O- $\alpha$-L-rhamnopyranosyl; RG: -(6-O-(6-deoxy- $\alpha$ L-mannopyranosyl)- $\beta$-D-glucopyranosyloxy); NG: -(2-O-(6-deoxy- $\alpha$-L-mannopyranosyl)- $\beta$-D-glucopyranosyl). 


\section{Materials and Methods}

\subsection{Materials and Methods}

Human colon adenocarcinoma cell line Caco-2 (ATCC \#HTB-37) was purchased from American Type Culture Collection (ATCC) (Rockville, MD, USA). 3-(4,5-dimethylthiazol-2-yl)-2,5-diphenyltetrazolium bromide (MTT) was purchased from Gen-View Scientific Inc. (Calimesa, CA, USA). Compound 1 and $\mathbf{2}$ were purchased from BBT INC. (Tianjin, China) (purity $>98 \%$ ). Compound 8 was purchased from Shanghai Tauto Biotech Co., Ltd. (Shanghai, China) (purity > 98\%). Compound 16 (purity > 95\%) and Lucifer yellow carbohydrazide $(\mathrm{CH})$ were purchased from Sigma-Aldrich (St. Louis, MO, USA). The remaining flavonoid compounds were purchased from Aladdin Chemistry Co., Ltd. (Shanghai, China) (purity $>98 \%$ ). The flavonoids were dissolved in stock with a concentration of $100 \mathrm{mM}$ anddiluted to a final concentration of $0.1 \%(v / v)$ dimethyl sulfoxide. Fetal bovine serum (FBS) was obtained from Gibco Laboratories (Life Technologies Inc., Grand Island, NY, USA). Minimum essential medium (MEM) and non-essential amino acids (NEAA) were purchased from Hyclone (Logan, UT, USA). Millicell hanging cell culture inserts of 12 wells (PET, $12 \mathrm{~mm}$, pore size $0.4 \mu \mathrm{m}$ ) were purchased from Millipore (Boston, MA, USA) and 12-well plates were purchased from Corning Costar (Cambridge, MA, USA). All other chemicals were of analytical grade.

\subsection{Cell Viability Assay}

The cytotoxicity of flavonoids and colchicine was evaluated by MTT assay. The cells were grown in 96-well plates at a density of $1 \times 10^{4}$ cells /well. After incubation with $40 \mu \mathrm{M}$ flavonoid for $24 \mathrm{~h}$, the cells were further incubated with an MTT solution $(0.5 \mathrm{mg} / \mathrm{mL})$ for $4 \mathrm{~h}$ at $37^{\circ} \mathrm{C}$. Finally, after removal of the supernatant, $150 \mu \mathrm{L}$ dimethyl sulphoxide was added to each well to dissolve crystallized MTT. Absorbance was read at $570 \mathrm{~nm}$ with a multiskan spectrum microplate reader (Thermo Labsystems, Waltham, MA, USA). The percentage cell viability relative to that of the control cells was used as the cytotoxicity measure.

\subsection{The Permeability of Flavonoids in Caco-2 Cell Monolayers}

Caco- 2 cells were cultured in MEM supplemented with 10\% FBS, 1\% NEAA, penicillin (100 U/mL) and streptomycin $(100 \mu \mathrm{g} / \mathrm{mL})$ in an atmosphere of $5 \% \mathrm{CO}_{2}$ and $90 \%$ relative humidity at $37{ }^{\circ} \mathrm{C}$. All cells used in this study were between passages 35 and 45 [16].

Caco- 2 cells were seeded at a density of about $8 \times 10^{4}$ cells $/ \mathrm{cm}^{2}$ on a 12 wells Millicell hanging insert and left to grow for 19-21 days to reach confluence. Culture medium was replaced every other day for 14 days and daily thereafter. The integrity and transport ability of the Caco-2 cells monolayer were examined by measuring the trans-epithelial electrical resistance (TEER) with a Millicell voltammeter (Millicell ERS-2, Merck Millipore, Billerica, MA, USA) and running standard assays using Lucifer yellow $\mathrm{CH}$ as paracellular flux marker. Only cell monolayers with a TEER above $600 \Omega \cdot \mathrm{cm}^{2}$ and $P_{\text {app }}$ of Lucifer yellow $\mathrm{CH}$ flux less than $0.5 \times 10^{-6} \mathrm{~cm} / \mathrm{s}$ were used for the transport assays. Differentiation of Caco- 2 cells was checked after 4 and 12 days by determining the activity of alkaline phosphatase with an assay kit (Nanjing Jiancheng Bioengineering Institute, Nanjing, China) and after 21 days transmission electron microscopy was performed on Caco-2 monolayer to evaluate differentiation [17].

The Caco-2 cell monolayer was washed with D-Hank's buffer ( $\mathrm{pH} 7.4$ ). Then, the flavonoid $(40 \mu \mathrm{M})$ was added to either the apical (AP, $0.4 \mathrm{~mL})$ or basolateral $(\mathrm{BL}, 1.95 \mathrm{~mL})$ side, while the receiving chamber contained the corresponding volume of D-Hank's buffer and incubated for $1 \mathrm{~h}$ at $37^{\circ} \mathrm{C}$. Solutions from both AP and BL sides of Caco- 2 cell monolayer were collected and immediately frozen, lyophilized and preserved at $-80^{\circ} \mathrm{C}$ for high performance liquid chromatography (HPLC) analysis. $P_{\text {app }}$ was calculated from Equation (1), where $\Delta Q / \Delta t$ is the rate of the flavonoid on the 
accepting chamber $(\mu \mathrm{M} / \mathrm{s}), A$ is the surface area of the hanging insert $\left(\mathrm{cm}^{2}\right)$ and $C_{0}$ is the initial concentration of tested flavonoid in donating chamber $(\mu \mathrm{M} / \mathrm{mL})$.

$$
P_{\text {app }}=\frac{\Delta Q / \Delta t}{A C_{0}}
$$

\subsection{The CA of Flavonoids in Caco-2 Cell Monolayer}

After the collection of samples from both AP and BL sides, the hanging insert was rinsed twice with ice-cold D-Hank's buffer to stop further transport, and lysed with $0.1 \%$ Triton X-100 in D-Hank's buffer then placed in an ultrasonic bath for $15 \mathrm{~min}$. Cell lysates were collected and centrifuged at $7000 \times g$ for $10 \mathrm{~min}$. Supernatants were analyzed by BCA kit (Dingguochangsheng Biotechnology, Beijing, China) for protein content. After protein content assay, supernatants were immediately frozen, lyophilized and preserved at $-80^{\circ} \mathrm{C}$. The flavonoid concentration in lysis solution was determined by HPLC and normalized with cellular protein content.

\subsection{HPLC Assays of Flavonoids}

To determine both the permeability and CA of flavonoids in Caco-2 cells, the lyophilized samples were dissolved in running 120 to $200 \mu \mathrm{L}$ methanol, and centrifuged at $7000 \times g$ for $5 \mathrm{~min}$. Aliquot of $20 \mu \mathrm{L}$ of the supernatant solution was used for assay using Waters e2695 HPLC system (Milford, MA, USA) fitted with an Amethyst C18-H column $(250 \mathrm{~mm} \times 4.6 \mathrm{~mm}$ i.d., $5 \mu \mathrm{m}$; Sepax, Newark, DE, USA). The mobile phase consisted of $\mathrm{A}\left(0.01 \mathrm{M}\right.$ phosphoric acid $\left.\left(\mathrm{H}_{3} \mathrm{PO}_{4}\right)\right) / \mathrm{B}$ (acetonitrile) with $1.0 \mathrm{~mL} / \mathrm{min}$ flow rate. The assay was performed using the following gradient: $0-5 \mathrm{~min}: 95 \% \mathrm{~A}$; 5-10 min: 95-50\% A; 10-20 min: 50\% A; 20-22 min: 50-95\% A; 22-30 min: 95\% A. Elution peaks were monitored with a diode-array detector at the wavelength of maximum absorption of each flavonoid (200-400 nm). Peak area measurement was used to obtain standard calibration curves to determine concentration of each flavonoid.

\subsection{D-QSPR Study}

The structures of 30 flavonoids were drawn by Chembiodraw ultra 12.0 and energy minimization was performed by Sybyl X-2.0 (Tripos Inc., St. Louis, MO, USA). The geometric structures of these compounds were optimized using the density functional methods (DFT) calculations at the level of Becke's-parameter hybrid functional (B3LYP) and polarized basis sets 6-31G $(d, p)$. The electronic and topological descriptors and molecular properties were calculated by Gaussian 09 program package, Sybyl X-2.0 and molecular operating environment (MOE) 2009.

The $\mathrm{p} P_{\text {app A to B }}\left(-\log \left(P_{\text {app A to B }}\right)\right)$ was used as the dependent variable and descriptors were used as independent variables in the 2D-QSPR study. Twenty-two compounds were chosen by random as the training set to build the QSPR model and the remaining six compounds $(\mathbf{9}, \mathbf{1 2}, \mathbf{1 4}$, 20, 27 and 30) were used as the test set. Correlation analysis was performed by stepwise linear regression and bivariate methods to select the molecular descriptors affecting the permeability of flavonoids. Collinear descriptors, with the absolute value of inter-correlation coefficient $(R)$ higher than 0.7, were omitted [18]. The 2D-QSPR model was achieved using the partial least squares (PLS) algorithms with default parameters in Sybyl X-2.0. The resulting model was validated by using cross-validation (leave-one-out) procedures. Cross-validation coefficient $\left(Q^{2}\right)$ should be more than 0.5 for a reliable model [3]. The root-mean-square error (RMSE) for the training set was measured as shown in Equation (2) to evaluate the predictability of the developed model [19].

$$
\text { RMSE }=\sqrt{\frac{\sum_{i=1}^{n}\left(Y_{\text {iexp. }}-Y_{\text {ipred. }}\right)^{2}}{n}}
$$




\subsection{Statistical Analysis}

Statistical differences were determined by student's $t$ test on SPSS 16.0 and $p$ values less than 0.05 and 0.01 were considered significant and very significant, respectively.

\section{Results}

\subsection{Cell Viability}

Cell viability was evaluated in Caco-2 cells treated with $40 \mu \mathrm{M}$ flavonoid. As shown in Table 2, there is no significant difference $(p<0.05)$ between the Caco- 2 cell viability of the control and each flavonoid. These results indicated that the flavonoids at the tested concentration showed no cytotoxicity to Caco-2 cells.

Table 2. The cell viability of 30 flavonoids in Caco-2 cells.

\begin{tabular}{cccccc}
\hline No. & Cell Viability (\%) & No. & Cell Viability (\%) & No. & Cell Viability (\%) \\
\hline $\mathbf{1}$ & $96.32 \pm 9.79^{a}$ & $\mathbf{1 2}$ & $100.22 \pm 4.53^{a}$ & $\mathbf{2 3}$ & $94.60 \pm 3.60^{a}$ \\
$\mathbf{2}$ & $97.52 \pm 3.53^{a}$ & $\mathbf{1 3}$ & $101.77 \pm 6.15^{a}$ & $\mathbf{2 4}$ & $105.49 \pm 6.13^{a}$ \\
$\mathbf{3}$ & $97.68 \pm 8.39^{a}$ & $\mathbf{1 4}$ & $100.79 \pm 3.15^{a}$ & $\mathbf{2 5}$ & $98.35 \pm 4.60^{a}$ \\
$\mathbf{4}$ & $96.72 \pm 6.31^{a}$ & $\mathbf{1 5}$ & $93.64 \pm 1.22^{a}$ & $\mathbf{2 6}$ & $105.02 \pm 4.56^{a}$ \\
$\mathbf{5}$ & $100.66 \pm 4.19^{a}$ & $\mathbf{1 6}$ & $98.38 \pm 3.86^{a}$ & $\mathbf{2 7}$ & $103.27 \pm 3.37^{a}$ \\
$\mathbf{6}$ & $101.09 \pm 4.56^{a}$ & $\mathbf{1 7}$ & $105.78 \pm 5.48^{a}$ & $\mathbf{2 8}$ & $105.78 \pm 6.44^{a}$ \\
$\mathbf{7}$ & $103.02 \pm 4.94^{a}$ & $\mathbf{1 8}$ & $100.12 \pm 2.70^{a}$ & $\mathbf{2 9}$ & $99.18 \pm 7.94^{a}$ \\
$\mathbf{8}$ & $103.40 \pm 4.77^{a}$ & $\mathbf{1 9}$ & $95.60 \pm 3.47^{a}$ & $\mathbf{3 0}$ & $102.04 \pm 6.35^{a}$ \\
$\mathbf{9}$ & $106.20 \pm 7.79^{a}$ & $\mathbf{2 0}$ & $99.06 \pm 4.92^{a}$ & $\mathbf{C}$ & $100.00 \pm 4.38^{a}$ \\
$\mathbf{1 0}$ & $102.16 \pm 5.19^{a}$ & $\mathbf{2 1}$ & $100.74 \pm 4.27^{a}$ & & \\
$\mathbf{1 1}$ & $101.86 \pm 3.62^{a}$ & $\mathbf{2 2}$ & $99.48 \pm 2.00^{a}$ & & \\
\hline
\end{tabular}

C: Control. Results are presented as means \pm Standard Deviation (SD), $n=5$. Statistical comparisons were made using the one way ANOVA and a Duncan test. ${ }^{a}$ : Same letters mean there is no significance between the tested flavonoid and control in Caco-2 cells.

\subsection{Transport of Flavonoids}

Based on Caco-2 cell viability, the same nontoxic concentration $(40 \mu \mathrm{M})$ was used for all flavonoids in the transport studies to minimize error resulting from the concentration-dependent effect shown by some flavonoids.

The flavonoids permeated across the membrane to the acceptor compartments in both the apical to basolateral (A to B) and the basolateral to apical (B to A) assays. The results of bidirectional transport are summarized in Table 3. The flavonoid with the highest $P_{\text {app }}$ is $\mathbf{2 6}$ (a isoflavonoid) for both

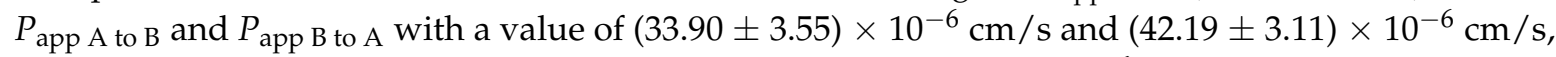
respectively, followed by 19, 21 and 27 with $P_{\text {app }}$ more than $30 \times 10^{-6} \mathrm{~cm} / \mathrm{s}$. Other isoflavonoid aglycones $\left(\mathbf{2 3}, \mathbf{2 5}\right.$, and 28 ) also showed good permeability with $P_{\text {app }}$ more than $10 \times 10^{-6} \mathrm{~cm} / \mathrm{s}$. Flavanone aglycones (18 and 22) also showed good intestinal absorption with high $P_{\text {app }}$ more than $20 \times 10^{-6} \mathrm{~cm} / \mathrm{s}$. These results indicate that isoflavonoids and flavanones show higher permeability than other flavonoids. Flavone aglycones display modest good intestinal absorption with $P_{\text {app }}$ greater than $6 \times 10^{-6} \mathrm{~cm} / \mathrm{s}$ while the low permeability $\left(<2 \times 10^{-6} \mathrm{~cm} / \mathrm{s}\right)$ of compound 4 results from the easily oxidized pyrogallic group. The flavonols with $P_{\text {app }}$ values less than $10 \times 10^{-6} \mathrm{~cm} / \mathrm{s}$ were poorly absorbed. The permeability of flavonols was lower than flavones by comparing 5 versus 10, 6 versus 12 and 7 versus 9, respectively. The hydroxyl group at position 3 may be unfavorable for flavonoids to pass through the cell membrane, leading to low permeability for flavonols from both apical and basolateral sides. Flavonoid glycosides $\left(8,16,17,20,24\right.$ and 30) showed low $P_{\text {app }}$ values $\left(<6 \times 10^{-6} \mathrm{~cm} / \mathrm{s}\right)$, suggesting that the presence of glycosidic group is also unfavorable for the absorption of flavonoids. 
Table 3. Apparent permeability coefficients $\left(P_{\text {app }}\right)$ of flavonoids in Caco-2 monolayer.

\begin{tabular}{|c|c|c|c|c|c|c|c|}
\hline No. & $P_{\text {app A to B }} \times 10^{-6} \mathrm{~cm} / \mathrm{s}$ & $P_{\text {app B to A }} \times 10^{-6} \mathrm{~cm} / \mathrm{s}$ & Ratio $_{p}$ & No. & $P_{\text {app A to B }} \times 10^{-6} \mathrm{~cm} / \mathrm{s}$ & $P_{\text {app B to A }} \times 10^{-6} \mathrm{~cm} / \mathrm{s}$ & Ratio $_{p}$ \\
\hline 1 & $22.35 \pm 1.37$ & $21.73 \pm 1.21$ & 0.97 & 16 & $4.24 \pm 1.25$ & $5.96 \pm 1.20$ & 1.41 \\
\hline 2 & $21.86 \pm 0.585$ & $23.94 \pm 0.45$ & 1.10 & 17 & $4.04 \pm 0.07$ & $4.28 \pm 0.44$ & 1.06 \\
\hline 3 & $16.43 \pm 1.20$ & $18.07 \pm 1.62$ & 1.10 & 18 & $23.50 \pm 0.85$ & $27.92 \pm 2.76$ & 1.19 \\
\hline 4 & $1.95 \pm 0.53$ & $0.71 \pm 0.21$ & 0.37 & 19 & $32.13 \pm 2.98$ & $35.34 \pm 1.16$ & 1.10 \\
\hline 5 & $10.10 \pm 7.33$ & $21.45 \pm 2.12$ & 2.12 & 20 & $3.73 \pm 0.73$ & $5.09 \pm 1.55$ & 1.36 \\
\hline 6 & $17.12 \pm 1.72$ & $16.92 \pm 1.02$ & 0.99 & 21 & $30.97 \pm 0.80$ & $36.96 \pm 1.97$ & 1.19 \\
\hline 7 & $6.78 \pm 0.12$ & $8.41 \pm 0.62$ & 1.24 & 22 & $6.32 \pm 1.16$ & $26.08 \pm 2.08$ & 4.13 \\
\hline 8 & $3.28 \pm 0.32$ & $2.81 \pm 0.24$ & 0.86 & 23 & $17.42 \pm 1.78$ & $18.31 \pm 1.83$ & 1.05 \\
\hline 9 & $1.94 \pm 0.41$ & $1.75 \pm 0.44$ & 0.90 & 24 & $2.25 \pm 0.96$ & $2.70 \pm 0.41$ & 1.20 \\
\hline 10 & $2.55 \pm 1.45$ & $4.68 \pm 0.41$ & 1.84 & 25 & $12.45 \pm 0.91$ & $6.23 \pm 0.46$ & 0.50 \\
\hline 11 & $8.23 \pm 0.87$ & $21.58 \pm 0.32$ & 2.62 & 26 & $33.90 \pm 3.55$ & $42.19 \pm 3.11$ & 1.24 \\
\hline 12 & $6.68 \pm 0.93$ & $5.92 \pm 0.45$ & 0.89 & 27 & $31.07 \pm 2.13$ & $30.48 \pm 2.13$ & 0.98 \\
\hline 13 & $0.35 \pm 0.06$ & $0.23 \pm 0.03$ & 0.66 & 28 & $11.11 \pm 0.51$ & $10.70 \pm 2.98$ & 0.96 \\
\hline 14 & $0.29 \pm 0.01$ & $0.44 \pm 0.01$ & 1.50 & 29 & $13.76 \pm 0.73$ & $20.04 \pm 1.29$ & 1.46 \\
\hline 15 & $1.09 \pm 0.02$ & $0.90 \pm 0.42$ & 0.83 & 30 & $4.25 \pm 0.53$ & $5.08 \pm 1.08$ & 1.20 \\
\hline
\end{tabular}

Most of the flavonoids exhibited a ratio ${ }_{p}$ ranging 0.8-1.5 (Table 3), suggesting that transport of these flavonoids is by passive diffusion. However, compounds 5, $\mathbf{1 1}$ and $\mathbf{2 2}$ with ratio $p>2.0$, exhibit efflux in Caco-2 monolayer. The absorption for compounds 4 and 25 (ratio $p<0.5$ ) is good, and also indicates higher absorption from apical to basolateral side.

\subsection{CA of Flavonoids in Caco-2 Cell Monolayers}

The $\mathrm{CA}$ in cells from apical to basolateral side $\left(\mathrm{CA}_{\mathrm{A}}\right.$ to $\left.\mathrm{B}\right)$ and basolateral to apical side $\left(\mathrm{CA}_{\mathrm{B}}\right.$ to $\left.\mathrm{A}\right)$ of flavonoids after transport are summarized in Table 4. The CA from both sides (CA $A$ to $B$ and $\mathrm{CA}_{\mathrm{B} \text { to } \mathrm{A}}$ ) of flavonoids 14, 16, 17, 22, and 24 were not detected. The other two flavonoid glycosides 8 and 30 also showed very low $\mathrm{CA}(<0.26 \mu \mathrm{mol} / \mathrm{g})$, suggesting that both the accumulation of flavonoid glycosides and their transport (low $P_{\text {app }}$ ) were poor. This may result from the low hydrophobicity of these flavonoids, which makes penetration through the phospholipid bilayer cell membrane difficult. Compound 14, with an unstable pyrogallic group, is easily autoxidized, resulting in low concentration both in cells (not detected) and transport chamber $\left(P_{\text {app }}<0.5 \times 10^{-6} \mathrm{~cm} / \mathrm{s}\right)$. Compounds 19, 21, 26 and 27 showed low CA values $(<5 \mu \mathrm{mol} / \mathrm{g})$ compared with their highest $P_{\text {app }}\left(>30 \times 10^{-6} \mathrm{~cm} / \mathrm{s}\right)$. Compounds 12 and 28 showed highest CA $(>6 \mu \mathrm{mol} / \mathrm{g})$ with modest $P_{\text {app }}$. These results suggest that the concentration of flavonoid aglycones accumulated in cells is not correlated with cell penetration. This is confirmed by the poor correlation coefficient $\left(R^{2}<0.3\right)$ between the $P_{\text {app }}$ and their corresponding CA.

Table 4. The cellular accumulation (CA) of flavonoids in Caco-2 monolayer.

\begin{tabular}{|c|c|c|c|c|c|c|c|}
\hline No. & $\mathrm{CA}_{\mathrm{A} \text { to } \mathrm{B}}(\mu \mathrm{mol} / \mathrm{g})$ & $\mathrm{CA}_{\mathrm{B} \text { to } \mathrm{A}}(\mu \mathrm{mol} / \mathrm{g})$ & Ratio $_{c}$ & No. & $\mathrm{CA}_{\mathrm{A} \text { to } \mathrm{B}}(\mu \mathrm{mol} / \mathrm{g})$ & $\mathrm{CA}_{\mathrm{B}}$ to $\mathrm{A}(\mu \mathrm{mol} / \mathrm{g})$ & Ratio $_{c}$ \\
\hline 1 & $1.932 \pm 0.051$ & $3.183 \pm 0.504^{a}$ & 1.65 & 16 & ND & ND & - \\
\hline 2 & $2.706 \pm 0.174$ & $2.423 \pm 0.543$ & 0.90 & 17 & $\mathrm{ND}$ & ND & - \\
\hline 3 & $1.038 \pm 0.212$ & $1.586 \pm 0.045$ & 1.53 & 18 & $1.293 \pm 0.086$ & $1.644 \pm 0.300$ & 1.27 \\
\hline 4 & $1.182 \pm 0.341$ & $3.272 \pm 0.445^{a}$ & 2.77 & 19 & $1.935 \pm 0.305$ & $4.436 \pm 0.299^{b}$ & 2.29 \\
\hline 5 & $3.876 \pm 0.741$ & $8.639 \pm 1.275^{b}$ & 2.23 & 20 & $0.058 \pm 0.013$ & $0.068 \pm 0.011$ & 1.17 \\
\hline 6 & $4.415 \pm 0.467$ & $7.610 \pm 0.694^{b}$ & 1.72 & 21 & $0.635 \pm 0.146$ & $1.234 \pm 0.249^{a}$ & 1.94 \\
\hline 7 & $3.902 \pm 0.251$ & $8.828 \pm 0.213^{b}$ & 2.26 & 22 & ND & ND & - \\
\hline 8 & $0.024 \pm 0.002$ & $0.044 \pm 0.007$ & 1.83 & 23 & $3.819 \pm 1.320$ & $4.842 \pm 0.424$ & 1.27 \\
\hline 9 & $3.780 \pm 0.711$ & $9.286 \pm 0.859^{b}$ & 2.46 & 24 & ND & $\mathrm{ND}$ & - \\
\hline 10 & NT & NT & - & 25 & $1.821 \pm 0.774^{a}$ & $0.158 \pm 0.021$ & 0.09 \\
\hline 11 & $0.129 \pm 0.008^{b}$ & $0.060 \pm 0.011$ & 0.464 & 26 & $0.500 \pm 0.104$ & $1.236 \pm 0.117^{b}$ & 2.47 \\
\hline 12 & $8.368 \pm 1.039$ & $11.887 \pm 1.247^{a}$ & 1.42 & 27 & $1.415 \pm 0.276$ & $2.777 \pm 0.220^{b}$ & 1.96 \\
\hline 13 & $2.746 \pm 0.478^{b}$ & $0.496 \pm 0.249$ & 0.18 & 28 & $6.766 \pm 1.583$ & $14.087 \pm 1.287^{b}$ & 2.08 \\
\hline
\end{tabular}


Table 4. Cont.

\begin{tabular}{cccccccc}
\hline No. & CA $_{\text {A to B }}(\mu \mathrm{mol} / \mathbf{g})$ & CA $_{\text {B to A }}(\mu \mathrm{mol} / \mathbf{g})$ & Ratio $_{\mathbf{c}}$ & No. & CA $_{\text {A to B }}(\mu \mathrm{mol} / \mathbf{g})$ & CA $_{\text {B to A }}(\mu \mathrm{mol} / \mathbf{g})$ & Ratio $_{\mathbf{c}}$ \\
\hline $\mathbf{1 4}$ & $\mathrm{ND}$ & $\mathrm{ND}$ & - & $\mathbf{2 9}$ & $4.393 \pm 0.790$ & $8.804 \pm 1.576^{a}$ & 2.00 \\
$\mathbf{1 5}$ & $0.332 \pm 0.066^{a}$ & $0.076 \pm 0.048$ & 0.23 & $\mathbf{3 0}$ & $0.096 \pm 0.010$ & $0.251 \pm 0.012$ & 2.61 \\
\hline
\end{tabular}

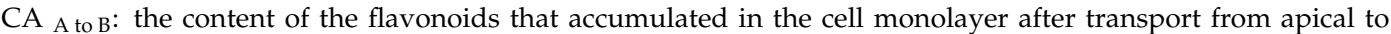
basolateral side. $\mathrm{CA}_{\mathrm{B} \text { to } \mathrm{A}}$ : the content of the flavonoids that accumulated in the cell monolayer after transport from basolateral to apical side. Ratio ${ }_{\mathrm{C}}$ : the ratio of $\mathrm{CA}_{\mathrm{B} \text { to A }}$ to $\mathrm{CA}_{\mathrm{A} \text { to } \mathrm{B}}$. Data are means $\pm \mathrm{SD}, n=3 .{ }^{a}$ : means $p<0.05$,

${ }^{b}$ : means $p<0.01$ in $t$ test. ND: not detected. NT: not tested.

The ratio ${ }_{c}$ was within the range of $0.09-2.77$, as shown in Table 4 . The ratio ${ }_{c}$ values for most of the compounds (except compounds $\mathbf{2}, \mathbf{1 3}, \mathbf{1 5}$ and 25) were more than 1.00, implying greater accumulation of flavonoids in the basolateral to apical direction. The $\mathrm{CA}_{\mathrm{A}}$ to $\mathrm{B}$ exhibited significant $(p<0.05$ or $p<0.01$ ) differences from the $\mathrm{CA}_{\mathrm{B}}$ to A for most of the flavones (except compound 2 and $\mathbf{3}$ ), isoflavones (except compound 23) and all of the flavonols. These results indicated that flavonoids accumulated in Caco-2 cells to a different extent during bilateral transport.

\subsection{Stability of Flavonoids}

In our initial study (data not shown), we found that methanol is a good solvent for the dissolution of flavonoids, even better than the mobile phase B (acetonitrile) used in HPLC assay. Hence, we evaluated the stability of flavonoids in different solvents with methanol as a standard solvent. The relative stability was expressed as the relative appearance of flavonoids in different solvents. Each flavonoid $(20 \mu \mathrm{M})$ was dissolved in two different solvents, D-Hank's and methanol. The relative concentration of flavonoid in D-Hank's was calculated by Equation (3) with results summarized in Table 5 . The relative concentration was more than $50 \%$ for most of the tested flavonoids, suggesting that most flavonoids are stable in D-Hank's buffer. However, the values of 4,13 and 14 were lower than $40 \%$, suggesting that these flavonoids are unstable in D-Hank's buffer. That could explain the low experimental $P_{\text {app }}$ of these three flavonoids.

Relative concentration in D-Hank's $(\%)=$ Peak area in D-Hank's $/$ Peak area in methanol $\times 100 \%$

Table 5. Flavonoid stability.

\begin{tabular}{|c|c|c|c|c|c|}
\hline \multicolumn{6}{|c|}{ Relative Concentration of Flavonoids } \\
\hline No. & D-Hank's/methanol (\%) & No. & D-Hank's/methanol (\%) & No. & D-Hank's/methanol (\%) \\
\hline 1 & 60.10 & 10 & 52.10 & 19 & 113.93 \\
\hline 2 & 12.09 & 11 & 79.06 & 20 & 64.99 \\
\hline 3 & 51.64 & 12 & 98.60 & 21 & 71.02 \\
\hline 4 & 34.12 & 13 & 7.25 & 24 & 30.31 \\
\hline 5 & 87.51 & 14 & ND & 25 & 85.60 \\
\hline 6 & 41.76 & 15 & 90.67 & 26 & 74.83 \\
\hline 7 & 47.63 & 16 & 116.67 & 27 & 88.16 \\
\hline 8 & 72.75 & 17 & 66.82 & 28 & 81.33 \\
\hline 9 & 105.96 & 18 & 115.83 & 29 & 131.85 \\
\hline \multicolumn{6}{|c|}{ Recovery of 7 Flavonoid Glycosides } \\
\hline No. & Recovery (B to A, \%) & RSD (\%) & Recovery (A to B, \%) & RSD (\%) & \\
\hline 8 & $61.83 \pm 0.72$ & 1.16 & $72.31 \pm 18.76$ & 25.96 & \\
\hline 11 & $90.12 \pm 1.39$ & 1.56 & $81.45 \pm 6.70$ & 8.22 & \\
\hline 16 & $76.77 \pm 9.36$ & 12.19 & $90.69 \pm 8.85$ & 9.76 & \\
\hline 17 & $96.95 \pm 1.67$ & 1.72 & $98.18 \pm 4.74$ & 4.84 & \\
\hline 20 & $82.88 \pm 10.99$ & 13.26 & $93.17 \pm 7.62$ & 8.18 & \\
\hline 24 & $85.25 \pm 0.60$ & 0.70 & $87.42 \pm 3.31$ & 3.79 & \\
\hline 30 & $79.50 \pm 1.24$ & 1.58 & $78.66 \pm 1.30$ & 1.65 & \\
\hline
\end{tabular}

B to A: Recovery of transport of a flavonoid from basolateral to apical side. A to B: Recovery of transport of a flavonoid from apical to basolateral side. RSD: relative standard deviation. ND: not detected. 
The recovery of the flavonoid glycosides during the transport assays was determined by mass balance and was measured as total amount of the flavonoids on both sides of the insert and in the Caco- 2 cells. The recovery rate and relative standard deviation (RSD) values of seven flavonoid glycosides are shown in Table 5 . Recoveries were all greater than $60 \%$ for these flavonoid glycosides, indicating that flavonoid glycosides are stable during the transport assay, and the low permeability for these flavonoids is not due to their stability.

\subsection{Construction and Validation of the QSPR Model}

To evaluate the relationship between intestinal absorption and structure of flavonoids, a QSPR model was constructed with $\mathrm{p} P_{\text {app } \mathrm{A} \text { to } \mathrm{B}}$ as the dependent variable and physio-chemical properties descriptors as independent variables. Stepwise regression analysis was used for variable selection to obtain the best equation. At the beginning of modeling, compounds $\mathbf{4}$ and $\mathbf{1 3}$ with high residuals (experimental $\mathrm{p} P_{\text {app A to B minus predicted } \mathrm{p} P} P_{\text {app A to B }}>0.600$ ) were omitted as outliers. Several factors may contribute to the outlier status of these two compounds, including low permeability and structure uniqueness. For compound 4, a specific pyrogallic group makes it unstable, as illustrated by its low relative concentration (34.12\%) in D-Hank's, and it has been shown to be metabolically susceptible [20]. For compound 13, the low relative concentration (7.25\%) and highest predictive residual (1.011) led to the outlier of this compound. The best QSPR equation was obtained from 22 compounds in training set as shown in Equation (4).

$$
\begin{gathered}
\mathrm{p} P_{\text {app A to B }}=4.715+1.358 Q_{\mathrm{C} 3 \prime}+0.059 E_{-} \text {sol }+0.020 S \log P_{-} V 3+0.056 v s u r f \_I D 1 \\
R^{2}=0.881, R_{\text {adj }}^{2}=0.875, Q^{2}=0.810, F=44.509, p<0.01, \mathrm{RMSE}=0.141, \\
R_{\text {pred }}^{2}=0.842, R^{2}{ }_{\text {adj-pred }}=0.802, \mathrm{SEE}=0.156
\end{gathered}
$$

The correlation matrix between $\mathrm{p} P$ app A to $\mathrm{B}$ and the respective molecular properties are shown in Table 6. The correlation matrix showed that the properties are independent, demonstrating that the model in this study is robust. Moreover, the QSPR model was validated by cross-validation (leave-one-out) and a high cross-validated coefficient $\left(Q^{2}=0.810\right)$ was achieved. The $\mathrm{p} P$ app A to B both in training and test set is predicted by this QSPR model with a particularly high degree of accuracy (Figure 1). The predicted deviations of the tested compounds (except 14 and 15) both in training and test set were lower than 0.5 as shown in Table 7. The QSPR is considered of high predictive ability with a high value (0.841) of square of predictive correlation coefficient $\left(R^{2}\right.$ pred $)$ for the test set. In addition, the low RMSE value (0.242) also confirmed the accuracy of the developed model. These results illustrate that the QSPR model is robust and predictive, and could be used to predict the intestinal absorption of flavonoids.

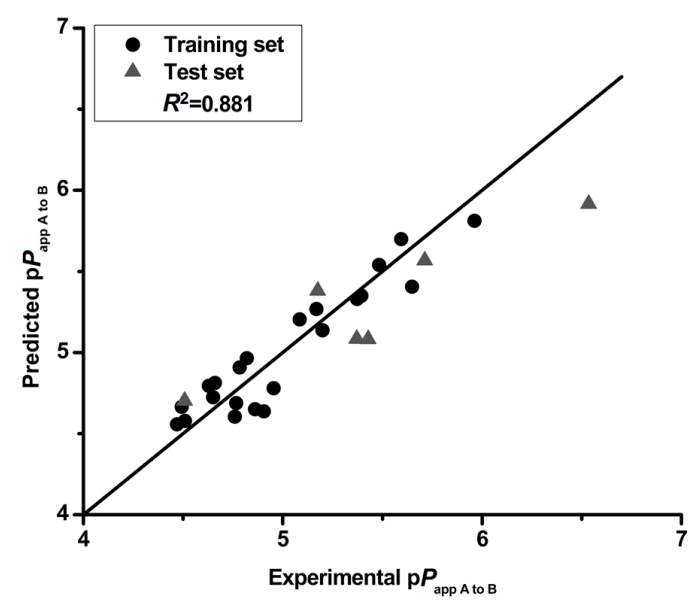

Figure 1. The experimental $\mathrm{p} P$ app A to B versus predicted $\mathrm{p} P$ app A to B. 
Table 6. The Pearson Correlation between $\mathrm{p} P$ app A to B and related descriptors.

\begin{tabular}{cccccc}
\hline & $\mathbf{p} P_{\text {app A to B }}$ & $Q_{\mathrm{C}^{\prime}}$ & $E_{-}$sol & SlogP_V3 & vsurf_ID1 \\
\hline $\mathrm{p} P_{\text {app A to B }}$ & 1.000 & $0.576^{* *}$ & 0.045 & $0.738^{* *}$ & 0.407 \\
$Q_{C 3^{\prime}}$ & & 1.000 & -0.273 & 0.223 & 0.214 \\
$E_{\text {_sol }}$ & & & 1.000 & -0.103 & -0.363 \\
SlogP_V3 & & & & 1.000 & -0.148 \\
vsurf_ID1 & & & & 1.000 \\
\hline
\end{tabular}

**: Correlation is significant at the 0.01 level.

Table 7. Calculated results using the QSPR model.

\begin{tabular}{ccccccccc}
\hline & No. & $\mathbf{p} \boldsymbol{P}_{\text {app A to B }}$ (Exper) & $\mathbf{p} \boldsymbol{P}_{\text {app A to B }}$ (Pred) & $\boldsymbol{E}_{-}$sol & SlogP_V3 & $Q_{\mathbf{C 3}^{\prime}}$ & vsurf_ID1 & Residuals \\
\hline & $\mathbf{1}$ & 4.651 & 4.756 & -0.789 & 0 & 0.010 & 0.736 & -0.105 \\
& $\mathbf{2}$ & 4.660 & 4.947 & -1.802 & 0 & -0.019 & 4.097 & -0.287 \\
& $\mathbf{3}$ & 4.784 & 4.803 & 1.526 & 0 & 0.011 & 1.561 & -0.019 \\
& $\mathbf{5}$ & 4.820 & 4.663 & -3.225 & 0 & 0.305 & 0.474 & 0.157 \\
& $\mathbf{6}$ & 4.766 & 4.751 & -0.893 & 0 & -0.007 & 0.636 & 0.015 \\
& $\mathbf{7}$ & 5.169 & 5.197 & 0.986 & 0 & 0.011 & 8.594 & -0.028 \\
& $\mathbf{8}$ & 5.484 & 5.709 & -2.750 & 41.853 & -0.004 & 2.774 & -0.225 \\
& $\mathbf{1 0}$ & 5.594 & 5.278 & 0.378 & 25.386 & 0.301 & 0.822 & 0.316 \\
& $\mathbf{1 1}$ & 5.085 & 5.243 & 0.104 & 25.386 & -0.033 & 0.359 & -0.158 \\
Training set & $\mathbf{1 5}$ & 5.962 & 5.322 & 1.610 & 25.386 & 0.322 & 1.034 & 0.640 \\
& $\mathbf{1 6}$ & 5.373 & 5.041 & -2.100 & 0 & 0.272 & 6.626 & 0.332 \\
& $\mathbf{1 7}$ & 5.394 & 5.363 & -10.491 & 20.927 & 0.276 & 8.232 & 0.031 \\
& $\mathbf{1 8}$ & 4.629 & 4.750 & 1.351 & 0 & -0.028 & 0.685 & -0.121 \\
& $\mathbf{1 9}$ & 4.493 & 4.754 & -1.043 & 0 & -0.018 & 0.669 & -0.261 \\
& $\mathbf{2 1}$ & 4.509 & 4.731 & -2.117 & 0 & -0.019 & 0.228 & -0.222 \\
& $\mathbf{2 2}$ & 5.199 & 4.755 & -0.789 & 0 & 0.302 & 1.064 & 0.444 \\
& $\mathbf{2 3}$ & 4.759 & 4.735 & -1.910 & 0 & -0.012 & 0.334 & 0.024 \\
& $\mathbf{2 4}$ & 5.648 & 5.370 & 1.320 & 20.927 & -0.034 & 4.292 & 0.278 \\
& $\mathbf{2 5}$ & 4.905 & 4.749 & -1.314 & 0 & -0.023 & 0.553 & 0.156 \\
& $\mathbf{2 6}$ & 4.470 & 4.730 & -2.317 & 0 & -0.023 & 0.190 & -0.260 \\
& $\mathbf{2 8}$ & 4.954 & 4.753 & 0.600 & 0 & -0.006 & 0.690 & 0.201 \\
& $\mathbf{2 9}$ & 4.861 & 4.765 & -1.601 & 0 & -0.013 & 0.861 & 0.096 \\
\hline
\end{tabular}

QSPR: quantitative structure-permeability relationship.

\subsection{QSPR Study}

In this study, four descriptors, namely $Q_{C 3^{\prime}}, E_{-} s o l, S \log P \_V 3$ and vsurf_ID1, were selected to build the QSPR model. This model showed that higher values for the descriptors results in a decrease in intestinal absorption of flavonoids. The significant Pearson coefficients between $Q_{\mathrm{C}^{\prime}}$ or $S \log P \_V 3$ and $\mathrm{p} P$ app A to $\mathrm{B}$ suggests that these two descriptors play major roles in the transport of flavonoids. The electronic properties of flavonoids are important for their absorption. The molecule charge of a flavonoid is electro-neutral, while, the electronic delocalization for each atom in a molecule varies with the number and position of substituents. The value of $Q_{\mathrm{C}^{\prime}}$ for each flavonoid is shown in Table 7, representing the atomic charges of carbon $3^{\prime}$ of the molecule. By comparing the $Q_{\mathrm{C}^{\prime}}$ and structure difference for tested flavonoids (Tables 1 and 7 ), the $\pi-\pi$-conjugation on $B$ ring makes this ring in a stable electron distribution and carbon $3^{\prime}$ with small positive atomic charges $(0.011)$ when without substitution at this position (1, 3, 4, 7 and 9). The atomic charges increased to higher positive atomic charges (approximately 0.300) with the presence of hydroxyl or methoxyl group $(\mathbf{5}, \mathbf{1 0}, \mathbf{1 4}, \mathbf{1 5}, \mathbf{1 6}$, 17, 22 and 30). The oxygen of hydroxyl/methoxyl group withdraws the electron(s) to the oxygen atom side leading to a loss of carbon $3^{\prime}$ electron(s) resulting in positive atomic charges for carbon $3^{\prime}$. This can be confirmed by comparing compound 27 and $\mathbf{2 9}$, with same $S \log P_{-} V 3$ and similar vsurf_ID1, 
although 29 has a lower $E \_s o l$ which favors absorption, 27 with a lower $Q_{\mathrm{C} 3^{\prime}}$ showed better absorption. The hydroxylation or methoxylation of adjacent carbon $4^{\prime}(2,6,8,11,19,20,21,24,25,26,27,28$ and 29) results in carbon $4^{\prime}$ having positive charges, and carbon $3^{\prime}$ having negative charges. Similarly, it can be presumed that substitution on carbon $2^{\prime}$ will also increase absorption. This is verified when evaluating flavonoids 11 and 12. Flavonoid 11 having negative charges on carbon $3^{\prime}$, with substitution both on carbon $2^{\prime}$ and carbon $4^{\prime}$ showed better absorption than 12 with substitution only on carbon $4^{\prime}$. These results suggest that the substitution by an electronegative group (such as a hydroxyl group) on carbon $3^{\prime}$ is unfavorable for flavonoid absorption while the substitution on adjacent carbon $\left(2^{\prime}\right.$ and $\left.4^{\prime}\right)$ favors absorption.

$S \log P_{-} V S A$ descriptors aim to capture hydrophilic and hydrophobic effects in the receptor and the atomic contribution to $\log \mathrm{P}$ was calculated by the Wildman and Crippen SlogP model [19]. SlogP_VSA3 $\left(S \log P_{-} V 3\right)$ represent the Van der Vaals surface area of the atoms contributing to the $\log \mathrm{P}(\mathrm{o} / \mathrm{w})$ of the molecule in the range $(0,0.1)$. High $S \log P_{-} V 3$ increases the molecular surface area, resulting in low absorption of flavonoids. For flavonols, the substitution of a hydroxyl group on position 3 increases $S \log P_{-} V 3$ to 25.386 . Flavonoid glycosides $(\mathbf{8}, \mathbf{1 7}, \mathbf{2 0}, 24$ and 30), with substitution of a glycosidic group also showed an increase in $S \log P_{-} V 3$ (>20.93). Flavonoid 8, having two glycosidic groups at two different positions (6 and 8 ), showed the highest $S \log P \_V 3$ value (41.853). These results suggest that the substitution of 3-OH or glycosidic group(s) is unfavorable for the absorption of flavonoids.

The vsurf descriptors relating to structure connectivity and conformation are similar to the VolSurf descriptors [21]. vsurf_ID1 is a hydrophobic integy moment vector pointing from the center of mass to the center of a hydrophobic region. The descriptor represents the unbalance between the center of mass of a molecule and the position of the hydrophobic regions around it at a $-0.2 \mathrm{kcal} / \mathrm{mol}$ energy level. A high integy moment indicates that the hydrophobic regions are clearly concentrated in only one part of the molecular surface. A small integy moment indicates that the barycenter is close to the center of the molecule. Compounds 25 and 26 displayed same $S \log P_{-} V 3$ and $Q_{\mathrm{C} 3^{\prime}}$ and similar $E_{-}$sol however 26 with lower vsurf_ID1 showed better absorption because 25 had an external methoxyl group on position 6 . The flavonoid glycosides $(\mathbf{8}, \mathbf{1 6}, \mathbf{1 7}, \mathbf{2 0}, 24$ and 30) showed high integy moment $(>2.7)$ resulting from bulky glycosidic group(s), which could aggravate the unbalance between the barycenter and hydrophobic region position. Flavonoids (5, 11, 21, 23 and 26) showed small integy moment $(<0.5)$. The numbers of substitution on A and B ring are the same for these flavonoids so that the barycenter is close to the center of the molecule. For compound 7, two hydroxyl groups (position 5 and 7) are far away from the center of mass leading to a high integy moment (8.594) which is similar to compound 2 also having a high integy moment (4.097). In summary, when the distribution of substituents is equal between A and B ring, the balance between the center of hydrophobic region and the center of mass will increase, resulting in high absorption of flavonoids. However, the substitution of a balky group (such as a glycosidic group) decreases the balance between the center of hydrophobic region and the center of mass, thereby decreasing the absorption of flavonoids.

E_sol is a 3D molecular descriptor, representing the solvation energy of flavonoids in the solvation process. The higher the energy is, the lower the resulting absorption. By comparing compounds 20 and 24, with same $S \log P_{-} V 3$ and $Q_{\mathrm{C}^{\prime}}$ and similar vsurf_ID1, compound 20, with lower E_sol showed better absorption. Similarly, with lower E_sol, compound 27 had higher absorption than 25 . For flavonoids 18 and 19, having similar $S \log P \_V 3$ and vsurf_ID1, 19 with much higher E_sol, showed better absorption than 18 despite having a slightly lower $Q_{\mathrm{C} 3^{\prime}}$. These results indicate that $E \_s o l$ is an important parameter related to the absorption of flavonoids.

\section{Discussion}

The bilateral permeation across the Caco-2 monolayer of selected five types of flavonoids (Table 1 ) followed the order: flavanones $\geq$ isoflavones $>$ flavones $\geq$ chalcones $>$ flavonols, which is consistent with previous results reported for the bioavailability of flavonoids (isoflavones $>$ flavanols $>$ flavanones $>$ flavonols $>$ anthocyanins) [22]. The permeability for most of 
tested flavonoids in this study is similar with the literature results $[5,16,23,24]$ since their bidirectional permeability was in the same order of magnitude. The bilateral permeation of flavonoids followed the order: $12>10>15$, consistent with a previous study [16]. The permeability of Lucifer yellow $\mathrm{CH}$ is also consistent with that reported in a previous study [16]. Our results indicate that the Caco-2 monolayer in this study is well suited to represent flavonoid transport and the data are valid.

Flavonoid glycoside 20 naringin, $\left(P_{\text {app }}<6 \times 10^{-6} \mathrm{~cm} / \mathrm{s}\right)$ showed much lower permeability than 19 naringenin, $\left(P_{\text {app }}>32.13 \times 10^{-6} \mathrm{~cm} / \mathrm{s}\right)$. The other flavonoid glycosides tested also showed low permeability $\left(P_{\text {app }}<6 \times 10^{-6} \mathrm{~cm} / \mathrm{s}\right)$. These results are in agreement with studies that concluded that glycosides are poorly absorbed compounds $[23,25]$. Poor lipid solubility and the presence of multiple hydroxyl groups are reported reasons contributing to the poor absorption of flavonoid glycosides [25]. However, the $P_{\text {app }}$ value reported is lower $\left(<1 \times 10^{-6} \mathrm{~cm} / \mathrm{s}\right)$ in previous studies $[23,26]$ than in our study. The discrepancy could be associated in part to the poor membrane permeability of these glycosides, as well as to different experimental conditions used. The CA of glycosides in this study are low $(<0.3 \mu \mathrm{mol} / \mathrm{g})$ or not detected which is agreement with a literature result [23]. Although the absorption of flavonoid glycosides in vitro is poor or not detected, it was confirmed that the absorption of quercetin glycosides in a human study with ileostomy subjects was higher than quercetin, implying that absorption of glycosides in the small intestinal is possible [27].

Flavonols showed lower permeability than corresponding flavones when comparing 5 versus 10, 6 versus 12 and 7 versus 9, suggesting 3-OH is unfavorable for flavonoid permeability. In addition, flavonoids 4, 9, 10, 13, 14 and 15, sharing three or more hydroxyl groups showed low permeability. The $P_{\text {app }}$ values increased adversely with the number of hydroxyl groups in a sub class of flavonoids as reported previously [22]. Possible explanation include excess free hydroxyl groups are easily autoxidized, especially the presence of a pyrogallic group which can easily bind hydrogen bonds with its aqueous environment [28] and rapid conjugation by glucuronidation and sulfation [29].

An influential predictive model for intestinal absorption is the "Lipinski rule-of 5", which resulted from the analysis of the World Drug Index [30]. Compounds that are likely absorbable through the intestines contain no more than $5 \mathrm{H}$-bond donors, $10 \mathrm{H}$-bond acceptors, have a molecular weight of $<500 \mathrm{Da}$ and $\log P$ (lipophilicity index) $<5$. According to this rule, flavonoids, with higher numbers of hydroxyl, or glycosidic moieties are less likely to be absorbed through the intestines which are in agreement with our results. In contrast, methoxylated flavonoids lose their H-bond acceptor/donor properties and have higher $\log P$ values, which make them highly absorbable. Compound 2 containing methoxyl groups showed high permeability, consistent with the literature that concluded methylation greatly improved intestinal absorption [31]. For flavonoids with only one methoxyl group, it is not certain that absorption will increase. Our study found that methoxylation increases the absorption when comparing compound 3 and 7, but decreases absorption by comparing 10 versus 15, 25 versus 26 and 27 versus 28 , respectively.

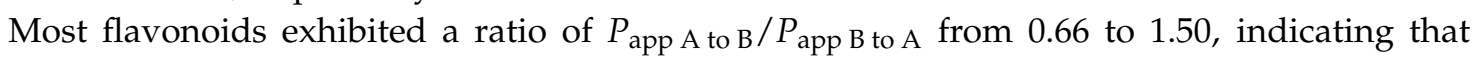
they permeate across the Caco-2 monolayer via passive diffusion. For compounds 5, 11 and 22, however, the hypothesis of active transport should not be excluded since the ratio $p$ is higher than 2 [15]. For 22, the ratio $p_{p}$ (4.13), is much higher than 2, suggesting an efflux mechanism which was also concluded in a previous study [32]. The transport mechanism of compound 10 with a high ratio $p(1.84)$, warrants further study since this compound has been reported to be pumped back by breast cancer resistance protein (BCRP) in the form of glucuronidated metabolites [33]. Chrysin (compound 7) has been shown to exhibit efflux in Caco-2 monolayer [34]. In this study, efflux of chrysin was not observed probably due to the design of HPLC assays for which only parental compound were determined with standard of chrysin. The relative concentration of chrysin in D-Hank's is less than $50 \%$, indicating that it is not stable in the buffer solution. Besides the rule of ratio $p$ [15], it is more concise and popular to use inhibitor of transporters to distinguish flavonoid absorption, especially, for poorly absorbed flavonoids. Further study is needed to focus on the efflux transport for flavonoids since it has been 
reported that passive diffusion and carrier-mediated efflux are known to be the two major pathways for a molecule to permeate across the intestinal epithelium [35].

Due to the wide range and variability in structure within each group, it is difficult to generalize the absorption of flavonoids based only on structure. Physio-chemical properties need to be taken into account to ascertain structure relationship to permeability. In this study, QSPR model was built to construct a mathematical relationship between the molecular structural descriptors and permeability ( $\left.P_{\text {app A to B }}\right)$. QSPR devoted to flavonoid absorption is limited in the literature. 2D and 3D QSPR models were constructed to explain and predict intestinal absorption of flavonoids using $P_{\text {app } A \text { to } \mathrm{B}}$ in Caco- 2 cells [9]. However, the data consisted of the log of the $P_{\text {app }}$ (transformed to $P_{\text {app }} \times 10^{-7}$ ), which omitted the part of $10^{-7}$ was not precise in the previous study [9]. The data were transformed to $\mathrm{p} P_{\text {app }}(-\log )$ in this study is more acceptable than the previous study [9]. Moreover, the atom-type electrotopological state (E-state) and weighted holistic invariant molecular (WHIM) descriptors used to develop QSPR model were reported to be cumbersome to interpret [9]. Therefore, no structure and permeability relationship was discussed with those models and those models only lies on their utility in screening of emerging flavonoids [9]. In addition, the 3D model (comparative molecular similarity index analysis, CoMSIA) reported in the literature was not suitable since CoMSIA is usually used for a target receptor (such as enzyme) [36] but not for permeability properties. Because the permeability of flavonoids can be influenced by several factors, such as pumped out by efflux transporters [24], interaction with membrane [5], stability, solubility and hydrophobicity of the compounds [37].

In QSPR analysis, hydrophobic, electronic and steric are the three major descriptors that must be included in analysis [38]. In our study, the descriptors used to build QSPR model were derived from more than one molecular modeling package, Gaussian 09, SYBYL X-2.0 and MOE 2009 including physical, electrostatic, topological, hydrophobic, and energetic descriptors. Physical 3D structure of flavonoids is indeed a determining factor for intestinal absorption since our QSPR model captured three $3 \mathrm{D}$ descriptors among four descriptors. $Q_{\mathrm{C}^{\prime}}$ used in our study representing the atomic charge on carbon $3^{\prime}$ is easily to interpret when comparing with those descriptors in previous study [9]. The substitution (methoxylation or hydroxylation) on carbon $3^{\prime}$ or adjacent positions affects $Q_{\mathrm{C} 3^{\prime}}$, and also affects flavonoid absorption. Hydroxylation or methoxylation at carbon $3^{\prime}$ will decrease absorption of a flavonoid while substitution on adjacent carbon $2^{\prime}$ or $4^{\prime}$ can increase the absorption. This type of descriptor has been successfully used in generating a quantitative structure-activity relationship (QSAR) model to predict antibacterial capacity against $E$. coli for flavonoids [3]. SlogP_V3 was proven to have a negative effect on absorption, which is consistent with a study that reported that an increase in polar surface area (PSA) was unfavorable for absorption [39]. Such descriptor has been successfully used in QSAR modeling of HIV-1 reverse transcriptase inhibition by benzoxazinones [36] and inhibition of potassium channel blockers [40]. It was found in this study that the presence of 3-OH or glycosidic group decreases flavonoid absorption according to SlogP_V3. vsurf_ID1 representing the balance of the molecule, indicates favorable absorption when the substitution is equal on A and $\mathrm{B}$ ring. Descriptors of this type were used to develop a model for discriminating P-gp substrates based on Caco-2 efflux ratio values [41]. E_sol describes the process of solubilisation of flavonoids and is utilized in the prediction of solubility [42]. The increasing of the energy will decrease the solubility thereby decrease flavonoids absorption. These descriptors generate a direct link between the molecular parameters of the model to the actual structural properties that govern the permeability and they are easy to interpret.

\section{Conclusions}

Oral bioavailability remains one of the most critical issues for flavonoids in nutrition and health. In this study, 30 flavonoids were tested for transepithelial permeability in Caco-2 cell monolayer. QSPR model was built to predict intestinal absorption of flavonoids by using structural characteristics and the model showed good predictive power. Four descriptors, $Q_{\mathrm{C}^{\prime}}, S \log P_{-} V 3$, vsurf_ID1 and E_sol, were found to relate to flavonoid absorption. Substitution of a negative group (such as - $\mathrm{OH}$ 
or $-\mathrm{OCH}_{3}$ ) on carbon $3^{\prime}$ decreases the flavonoid absorption while substitution on adjacent carbon $2^{\prime}$ or/and carbon $4^{\prime}$ increases the absorption. The presence of 3-OH or glycosidic group decrease the absorption of flavonoids. The equal substitution on A ring and B ring is also favorable for absorption. The results of this study are important in ascertaining the structural features important to flavonoid intestinal absorption.

Acknowledgments: This work was supported by the National Natural Science Foundation of China (31471625).

Author Contributions: X.X. and S.P. supervised this study and designed the experiments. X.X. wrote the manuscript. Y.F. designed and performed the experiments and wrote some parts of the manuscript. M.X. participated in data collection. W.C. performed the HPLC analysis. All authors reviewed the manuscript.

Conflicts of Interest: The authors declare no conflict of interest.

\section{Abbreviations}

$\begin{array}{ll}\text { CA } & \text { cellular accumulation } \\ \text { CoMSIA } & \begin{array}{l}\text { comparative molecular similarity index analysis } \\ \text { fetal bovine serum } \\ \text { hBS }\end{array} \\ \text { hPLC } & \text { minimum essential medium } \\ \text { MEM } & \text { non-essential amino acids } \\ \text { NEAA } & \text { the apparent permeability coefficient } \\ P_{\text {app }} & \text { partial least squares } \\ \text { PLS } & \text { structure-permeability relationship } \\ \text { SPR } & \text { quantitative structure-permeability relationship } \\ \text { QSPR } & \text { quantitative structure-activity relationship } \\ \text { QSAR } & \text { the root-mean-square error } \\ \text { RMSE } & \text { trans-epithelial electrical resistance } \\ \text { TEER } & \end{array}$

\section{References}

1. Halbwirth, H. The creation and physiological relevance of divergent hydroxylation patterns in the flavonoid pathway. Int. J. Mol. Sci. 2010, 11, 595-621. [CrossRef] [PubMed]

2. Cao, J.; Xia, X.; Chen, X.; Xiao, J.; Wang, Q. Characterization of flavonoids from Dryopteris erythrosora and evaluation of their antioxidant, anticancer and acetylcholinesterase inhibition activities. Food Chem. Toxicol. 2013, 51, 242-250. [CrossRef] [PubMed]

3. Wu, T.; He, M.; Zang, X.; Zhou, Y.; Qiu, T.; Pan, S.; Xu, X. A structure-activity relationship study of flavonoids as inhibitors of E. coli by membrane interaction effect. Biochim. Biophys. Acta 2013, 1828, 2751-2756. [CrossRef] [PubMed]

4. Cho, N.; Lee, K.Y.; Huh, J.; Choi, J.H.; Yang, H.; Jeong, E.J.; Kim, H.P.; Sung, S.H. Cognitive-enhancing effects of Rhus verniciflua bark extract and its active flavonoids with neuroprotective and anti-inflammatory activities. Food Chem. Toxicol. 2013, 58, 355-361. [CrossRef] [PubMed]

5. Tammela, P.; Laitinen, L.; Galkin, A.; Wennberg, T.; Heczko, R.; Vuorela, H.; Slotte, J.P.; Vuorela, P. Permeability characteristics and membrane affinity of flavonoids and alkyl gallates in Caco-2 cells and in phospholipid vesicles. Arch. Biochem. Biophys. 2004, 425, 193-199. [CrossRef] [PubMed]

6. Walle, T.; Ta, N.; Kawamori, T.; Wen, X.; Tsuji, P.A.; Walle, U.K. Cancer chemopreventive properties of orally bioavailable flavonoids-Methylated versus unmethylated flavones. Biochem. Pharmacol. 2007, 73, 1288-1296. [CrossRef] [PubMed]

7. Mukai, R.; Fujikura, Y.; Murota, K.; Uehara, M.; Minekawa, S.; Matsui, N.; Kawamura, T.; Nemoto, H.; Terao, J. Prenylation enhances quercetin uptake and reduces efflux in Caco-2 cells and enhances tissue accumulation in mice fed long-term. J. Nutr. 2013, 143, 1558-1564. [CrossRef] [PubMed]

8. Hollman, P.C.H.; Bijsman, M.N.C.P.; Gameren, Y.; Cnossen, E.P.J.; de Vries, J.H.M.; Katan, M.B. The sugar moiety is a major determinant of the absorption of dietary flavonoid glycosides in man. Free Radic. Res. 1991, 31, 569-573. [CrossRef] 
9. Gonzales, G.B.; Camp, J.V.; Zotti, M.; Kobayashi, V.; Grootaert, C.; Raes, K.; Smagghe, G. Two- and three-dimensional quantitative structure-permeability relationship of flavonoids in Caco-2 cells using stepwise multiple linear regression (SMLR), partial least squares regression (PLSR), and pharmacophore (GALAHAD)-based comparative molecular similarity index analysis (COMSIA). Med. Chem. Res. 2015, 24, 1696-1706. [CrossRef]

10. Qiu, J.; Kitamura, Y.; Miyata, Y.; Tamaru, S.; Tanaka, K.; Tanaka, T.; Matsui, T. Transepithelial transport of theasinensins through Caco-2 cell monolayers and their absorption in Sprague-Dawley rats after oral administration. J. Agric. Food Chem. 2012, 60, 8036-8043. [CrossRef] [PubMed]

11. Gallardo, E.; Sarria, B.; Espartero, J.L.; Correa, J.A.G.; Bravo-Clemente, L.; Mateos, R. Evaluation of the bioavailability and metabolism of nitroderivatives of hydroxytyrosol using Caco-2 and HepG2 human cell models. J. Agric. Food Chem. 2016, 64, 2289-2297. [CrossRef] [PubMed]

12. Yi, W.G.; Akoh, C.C.; Fischer, J.; Krewer, G. Absorption of anthocyanins from blueberry extracts by Caco-2 human intestinal cell monolayers. J. Agric. Food Chem. 2006, 54, 5651-5658. [CrossRef] [PubMed]

13. Halleux, C.; Schneider, Y.J. Iron absorption by intestinal epithelial cells: 1. Caco-2 cells cultivated in serum-free medium, on polyethyleneterephthalate microporous membranes, as an in vitro model. In Vitro Cell. Dev. Biol. 1991, 27, 293-302. [CrossRef]

14. Artursson, P.; Borchardt, R.T. Intestinal drug absorption and metabolism in cell cultures: Caco-2 and beyond. Pharm. Res. 1997, 14, 1655-1658. [CrossRef] [PubMed]

15. Artursson, P.; Karlsson, J. Correlation between oral drug absorption in humans and apparent drug permeability coefficients in human intestinal epithelial (Caco-2) cells. Biochem. Biophys. Res. Commun. 1991, 175, 880-885. [CrossRef]

16. Wang, Y.; Cao, J.; Zeng, S. Involvement of P-glycoprotein in regulating cellular levels of Ginkgo flavonols: Quercetin, kaempferol, and isorhamnetin. J. Pharm. Pharmacol. 2005, 57, 751-758. [CrossRef] [PubMed]

17. Yang, X.W.; Yang, X.D.; Wang, Y.; Ma, L.; Zhang, Y.; Yang, X.G.; Wang, K. Establishment of Caco-2 cell monolayer model and the standard operation procedure for assessing intestinal absorption of chemical components of traditional Chinese medicine. J. Chin. Integr. Med. 2007, 5, 634-641. [CrossRef]

18. Lameira, J.; Alves, C.N.; Moliner, V.; Silla, E. A density functional study of flavonoid compounds with anti-HIV activity. Eur. J. Med. Chem. 2006, 41, 616-623. [CrossRef] [PubMed]

19. Wildman, S.A.; Crippen, G.M. Prediction of physicochemical parameters by atomic contributions. J. Chem. Inf. Comput. Sci. 1999, 39, 868-873. [CrossRef]

20. Feng, Z.; Zhou, J.; Shang, X.; Kuang, G.; Han, J.; Lu, L.; Zhang, L. Comparative research on stability of baicalin and baicalein administrated in monomer and total flavonoid fraction form of Radix scutellariae in biological fluids in vitro. Pharm. Biol. 2017, 55, 1177-1184. [CrossRef] [PubMed]

21. Cruciani, G.; Crivori, P.; Carrupt, P.-A.; Testa, B. Molecular fields in quantitative structure-permeation relationships: The VolSurf Approach. J. Mol. Struct. Theochem. 2000, 503, 17-30. [CrossRef]

22. Manach, C.; Williamson, G.; Morand, C.; Scalbert, A.; Rémésy, C. Bioavailability and bioefficacy of polyphenols in humans. I. Review of 97 bioavailability studies. Am. J. Clin. Nutr. 2005, 81 (Suppl. 1), 230S-242S. [CrossRef] [PubMed]

23. Tian, X.; Yang, X.; Yang, X.; Wang, K. Studies of intestinal permeability of 36 flavonoids using Caco-2 cell monolayer model. Int. J. Pharm. 2009, 367, 58-64. [CrossRef] [PubMed]

24. Duan, J.; Xie, Y.; Luo, H.; Li, G.; Wu, T.; Zhang, T. Transport characteristics of isorhamnetin across intestinal Caco-2 cell monolayers and the effects of transporters on it. Food Chem. Toxicol. 2014, 66, 313-320. [CrossRef] [PubMed]

25. Conradi, R.A.; Hilgers, A.R.; Ho, N.F.; Burton, P.S. The influence of peptide structure on transport across Caco-2 cells. Pharm. Res. 1991, 8, 1453-1460. [CrossRef] [PubMed]

26. Serra, H.; Mendes, T.; Bronze, M.R.; Simplício, A.L. Prediction of intestinal absorption and metabolism of pharmacologically active flavones and flavanones. Bioorgan. Med. Chem. 2008, 16, 4009-4018. [CrossRef] [PubMed]

27. Hollman, P.C.H.; Katan, M.B. Absorption, metabolism and health effects of dietary flavonoids in man. Biomed. Pharmacother 1997, 51, 305-310. [CrossRef]

28. Van de, W.H.; Gifford, E. ADMET in silico modelling: Towards prediction paradise? Nat. Rev. Drug Discov. 2003, 2, 192-204. [CrossRef] [PubMed] 
29. Otake, Y.; Hsieh, F.; Walle, T. Glucuronidation versus oxidation of the flavonoid galangin by human liver microsomes and epatocytes. Drug Metab. Dispos. 2002, 30, 576-581. [CrossRef] [PubMed]

30. Lipinski, C.A.; Lombardo, F.; Dominy, B.W.; Feeney, P.J. Experimental and computational approaches to estimate solubility and permeability in drug discovery and development settings. Adv. Drug Deliv. Rev. 2001, 46, 3-26. [CrossRef]

31. Wen, X.; Walle, T. Methylated flavonoids have greatly improved intestinal absorption and metabolic stability. Drug Metab. Dispos. 2006, 34, 1786-1792. [CrossRef] [PubMed]

32. Wang, X.; Meng, M.; Gao, L.; Liu, T.; Xu, Q.; Zeng, S. Permeation of astilbin and taxifolin in Caco-2 cell and their effects on the P-gp. Int. J. Pharm. 2009, 378, 1-8. [CrossRef] [PubMed]

33. Sesink, A.L.; Arts, I.C.; de Boer, V.C.; Breedveld, P.; Schellens, J.H.; Hollman, P.C.; Russel, F.G. Breast cancer resistance protein (Bcrp1/Abcg2) limits net intestinal uptake of quercetin in rats by facilitating apical efflux of glucuronides. Mol. Pharmacol. 2005, 67, 1999-2006. [CrossRef] [PubMed]

34. Walle, U.K.; Galijatovic, A.; Walle, T. Transport of the flavonoid chrysin and its conjugated metabolites by the human intestinal cell line Caco-2. Biochem. Pharmacol. 1999, 58, 431-438. [CrossRef]

35. Stenberg, P.; Luthman, K.; Artursson, P. Virtual screening of intestinal drug permeability. J. Control. Release 2000, 65, 231-243. [CrossRef]

36. Balaji, S.; Karthikeyan, C.; Hari, N.M.N.S.; Trivedi, P. QSAR modelling of HIV-1 reverse transcriptase inhibition by benzoxazinones using a combination of P_VSA and pharmacophore feature descriptors. Bioorgan. Med. Chem. Lett. 2004, 14, 6089-6094. [CrossRef] [PubMed]

37. Yang, Y.; Bai, L.; Li, X.; Xiong, J.; Xu, P.; Guo, C.; Xue, M. Transport of active flavonoids, based on cytotoxicity and lipophilicity: An evaluation using the blood-brain barrier cell and Caco-2 cell models. Toxicol. In Vitro 2014, 28, 388-396. [CrossRef] [PubMed]

38. Hansch, C.; Steinmetz, W.E.; Leo, A.J.; Mekapati, S.B.; Kurup, A.; Hoekman, D. On the role of polarizability in chemical-biological interactions. J. Chem. Inf. Comput. Sci. 2002, 43, 120-125. [CrossRef] [PubMed]

39. Egan, W.J.; Merz, K.M.; Baldwin, J.J. Prediction of drug absorption using multivariate statistics. J. Med. Chem. 2000, 43, 3867-3877. [CrossRef] [PubMed]

40. Thai, K.-M.; Ecker, G.F. Classification models for hERG inhibitors by counter-propagation neural networks. Chem. Biol. Drug Des. 2008, 72, 279-289. [CrossRef] [PubMed]

41. Crivori, P.; Reinach, B.; Pezzetta, D.; Poggesi, I. Computational models for identifying potential p-glycoprotein substrates and inhibitors. Mol. Pharm. 2005, 3, 33-44. [CrossRef]

42. Newby, D.; Freitas, A.A.; Ghafourian, T. Decision trees to characterise the roles of permeability and solubility on the prediction of oral absorption. Eur. J. Med. Chem. 2015, 90, 751-765. [CrossRef] [PubMed] 